\title{
Regulación jurídica del secreto empresarial en el ordenamiento jurídico cubano
}

$$
* * * *
$$

\section{Dayanis María Rodríguez Hernández}

Universidad de Ciego de Ávila Máximo Gómez Báez

rodriguezhernandezdayanismaria@gmail.com

\section{Lorenzo Palmero Martín}

Registrador del Estado Civil, Dirección Municipal de Justicia, Santa Clara, Cuba palmero97m@gmail.com

\section{Kirenia González Bello}

Universidad de Ciego de Ávila Máximo Gómez Báez

gonzalezkirenia25@gmail.com

\section{Heidy Donis Vieites}

Universidad de Ciego de Ávila Máximo Gómez Báez

heidydv90@gmail.com

Recibido: 22 de octubre de 2021

Aceptado: 16 de noviembre de 2021

\section{Resumen}

La presente investigación abarca un análisis doctrinal del secreto empresarial como institución jurídica. El secreto empresarial constituye una institución legal de gran relevancia, en la medida que impulsa el desarrollo de la industria y los negocios mediante la protección de las informaciones y conocimientos que no resultan accesibles al público y constituyen un resultado ventajoso en el mercado. El marcado valor de índole económico-comercial que trasluce el secreto empresarial forja la implementación de medidas para su protección legal. Pese a las transformaciones 
realizadas en Cuba en materia de propiedad intelectual, aún se observan insuficiencias en cuanto a la regulación jurídica del secreto empresarial que merecen especial atención. La implementación de una normativa que regule sustantivamente la institución con remisión a normas desarrolladoras constituye una necesidad en cuanto a la protección de los empresarios y sus intereses. El tema en cuestión posee gran importancia en el proceso de actualización del modelo económico cubano, así como la protección de los derechos dentro de la industria nacional. Atendiendo a ello, se traza como objetivo general fundamentar la necesidad de la adecuada regulación del secreto empresarial en el ordenamiento jurídico cubano.

Palabras clave: secreto, empresarios, ventajas, información, competencia.

\title{
Legal Regulation of the Business Secret in the Cuban Legal Order
}

\begin{abstract}
The research entitled: Legal regulation of business secrecy in the Cuban legal system, covers a doctrinal analysis of business secrecy as a legal institution. Business secrecy constitutes a highly relevant legal institution insofar as it promotes the development of industry and business by protecting information and knowledge that is not accessible to the public and constitutes an advantageous result in the market. The marked value of an economic-commercial nature that transpires the business secret forges the implementation of legal protection measures. Despite the transformations carried out in Cuba in the area of Intellectual Property, there are still shortcomings in terms of the legal regulation of business secrecy that deserve special attention. The implementation of a norm that substantively regulates the institution with reference to developing norms constitutes a necessity regarding the protection of entrepreneurs and their interests. The issue in question is of great importance in the process of updating the Cuban economic model, as well as the protection of rights within the national industry. In view of this, the general objective is: To substantiate the need for the adequate regulation of business secrecy in the Cuban legal system.
\end{abstract}

Key words: secret, entrepreneurs, advantages, information, competition.

\section{Regulamento legal do segredo comercial na ordem jurídica cubana}

\section{Resumo}

A pesquisa intitulada: Regulação jurídica do sigilo comercial no ordenamento jurídico cubano, aborda uma análise doutrinária do sigilo comercial como instituição jurídica. O sigilo comercial constitui uma instituição jurídica de grande relevância na medida em que promove o desenvolvimento da indústria e dos negó- 
cios, protegendo informaçôes e conhecimentos que não são acessíveis ao público e constituem um resultado vantajoso para o mercado. $\mathrm{O}$ valor marcado de natureza econômico-comercial que transpira o segredo do negócio, forja a implementação de medidas judiciais de proteção. Apesar das transformaçóes ocorridas em Cuba na área da Propriedade Intelectual, ainda existem lacunas em termos de regulamentação jurídica do sigilo comercial que merecem atenção especial. A implementação de uma norma que regula substantivamente a instituição no que se refere às normas de desenvolvimento, constitui uma necessidade no que diz respeito à proteção dos empresários e de seus interesses. O tema em questão é de grande importância no processo de atualização do modelo econômico cubano, bem como na proteção de direitos na indústria nacional. Em vista disso, o objetivo geral é: Consubstanciar a necessidade de uma regulamentação adequada do sigilo comercial no ordenamento jurídico cubano.

Palavras-chave: segredo, empreendedores, vantagens, informação, competição.

\section{Introducción}

El surgimiento del secreto empresarial como institución jurídica tiene sus bases en el Estado moderno. Este estuvo marcado por el florecimiento de la Revolución Industrial y los avances generados en las más diversas industrias y economía internacional. El desarrollo de las investigaciones tecnológicas y su aplicación al sector comercial y de los servicios determinó que se transformara la situación existente hasta el momento: lo importante no era ya la manufacturación a gran escala, sino estudiar el mercado a fondo e identificar el producto que se deseaba (Aguilar, 2008, p. 3).

El secreto empresarial se encuentra integrado por las informaciones y conocimientos de carácter oculto que, por el valor que poseen, constituyen una ventaja comercial para la libre competencia de las empresas en el mercado. Se debe resguardar en lugares seguros y de forma compartimentada, evitando que, en caso de una apropiación indebida, no se apoderen de su contenido completo, sino de una parte de él.

El secreto empresarial es el mecanismo adecuado y pertinente para proteger la información que, dadas sus características económicas y comerciales, le genera una ventaja competitiva a su poseedor legítimo. Por ende, permite proteger de forma general y no limitada un abanico más amplio de información que la patente (Peñaranda Martes, 2017, párr. 20). 
Sanín Restrepo (2013) señala que el secreto empresarial no solamente es una forma de protección autónoma dentro de la propiedad industrial, sino que la violación de secretos empresariales es considerada una violación a las normas de competencia (p. 16). Comprende toda la información relativa a cualquier ámbito o esfera de la empresa, cuyo mantenimiento en reserva le proporciona a su titular una mejora o una ventaja competitiva. De esta manera, se liga el concepto del secreto empresarial al desarrollo de la empresa, ya que comprende información y conocimientos que hacen parte de la actividad empresarial (Díaz Pérez, 2015, p. 42).

La protección legal de la propiedad intelectual en Cuba se encuentra de manera general en un proceso de reajuste a las experiencias internacionales que, en su ámbito, resultan de carácter novedoso. El Decreto Ley 336 De las disposiciones contractuales de Propiedad Industrial en los Negocios Jurídicos comprende la figura desde una nueva perspectiva, denominándolo "información no divulgada". El propio cuerpo legal solo regula algunos aspectos relacionados con la licencia de utilización de la información no divulgada, dejando de lado elementos de importancia para la regulación de dicha institución jurídica, como la conceptualización de la información no divulgada, los requisitos, las consecuencias de su divulgación no autorizada, las obligaciones y derechos de las partes intervinientes.

En lo concerniente al secreto empresarial como institución jurídica, la normativa cubana resulta insuficiente, en tanto da solución a algunas cuestiones relacionadas con este por vía penal, civil y laboral, sin la existencia de una norma sustantiva que regule de manera especial la figura. La deficiente regulación provoca riesgos en el ámbito empresarial de manera general ante la posible vulneración de los derechos derivados de su protección jurídica frente a terceros, por lo que urge instituir las pautas doctrinales para el estudio del secreto empresarial, estableciendo un análisis crítico desde una perspectiva positiva para su adecuada aplicación en el ordenamiento jurídico cubano.

\section{Evolución histórica del secreto empresarial en cuba}

Desde que se comenzó con la comercialización de bienes y servicios que han sido demandados por los consumidores, las compañías han 
buscado formas para hacer que sus productos sean siempre los primeros en ser escogidos por sobre otros que ofrecen los competidores. Los elementos que caracterizan a cada uno de los productos los hacen únicos en el mercado a los efectos de su comercialización.

La referencia como secreto industrial se corresponde con la influencia de la Revolución Industrial en la economía internacional. El desarrollo de las investigaciones tecnológicas y su aplicación al sector comercial y de los servicios determinó que se transformara la situación existente hasta el momento; lo importante no era ya la manufacturación a gran escala, sino estudiar el mercado a fondo e identificar el producto que se deseaba.

En esta realidad se comienza a emplear el término "secretos comerciales", asociado no solo al campo técnico, sino también al comercial. La evolución actual de la actividad empresarial, la influencia de factores no solo tecnológicos y comerciales, sino también de organización, gestión y conocimientos cada vez más especializados han determinado que la doctrina más reciente se refiera a los secretos empresariales como categoría más general que incluye los antes empleados, considerándolo como una categoría de mayor alcance y, por tanto, más adecuada al tratamiento de la institución.

En el Decreto Ley 199 del año 1999 Sobre la Seguridad y Protección de la Información Oficial se evidencia la figura de los secretos estatales, cuya naturaleza no se identifica con la de los secretos empresariales. De la clasificación de estas informaciones se encarga la Comisión Estatal para la Clasificación y Desclasificación de la Información Oficial, la cual elabora y somete a la aprobación del Comité Ejecutivo del Consejo de Ministros su Lista General para la clasificación de las informaciones oficiales, en la que se enumera una relación de aquellas que se pretende sean consideradas como secretos estatales. ${ }^{1}$

Históricamente, el tratamiento de los secretos empresariales en Cuba, tanto desde el punto de vista teórico como jurídico, no ha tenido gran auge. En 1936 se encontraban algunos aspectos relacionados con el tema en la regulación del Código de Defensa Social, promulgado por el Decreto Ley 802 del 4 de abril de 1936.

1 Decreto Ley 199 Sobre la Seguridad y Protección de la Información Oficial, 2 de diciembre de 1999, Gaceta Oficial Ordinaria, número 78. 
En el título VIII sobre los Delitos contra los funcionarios públicos en el ejercicio de sus cargos y otros análogos se preveía la revelación de secretos, bien por parte de un funcionario público, empleado, abogado o por cualquier otra persona. ${ }^{2}$ Para esa fecha también existía el Decreto Ley 805 de 1936 de Propiedad Industrial, que establecía determinados elementos vinculados con la defraudación de los derechos de propiedad industrial para todo aquel que con medios engañosos lesionara derechos legítimos adquiridos por terceros.

La información oficial clasificada considerada secreto implica la protección de un conocimiento cuya revelación no autorizada puede causar perjuicios en las esferas política, militar, económica, científica, técnica, cultural, social o cualquier otra de importancia para el funcionamiento del Estado. Asimismo, queda centrado el objeto de protección en la seguridad estatal y los intereses de la colectividad.

Los secretos empresariales, por su parte, son en su mayoría informaciones o conocimientos con un valor económico significativo, por lo que en determinados momentos pueden llegar a tener significación como información oficial clasificada. Este carácter permite cobrar un interés general para la colectividad, ya sea en la defensa, en la salud o en la economía del país, pero ello solo ocurre en escazas ocasiones.

Los secretos estatales cuentan con una protección específica y encuentran respaldo en la vía penal. De esta manera, la connotación estatal y pública no se identifica con el tipo de protección que se le debe conferir a los secretos empresariales, pues se debe señalar sobre este particular la insuficiencia de regulación

La Resolución No. 21 de 2002 del Ministerio de Ciencia Tecnología y Medio Ambiente (CITMA), Sistema Nacional de Propiedad Industrial, en su segundo epígrafe referido a los principios generales del sistema nacional, hace alusión indistintamente a los términos "secreto", know how, "información oficial", "información no divulgada", "informaciones técnicas, de producción", "informaciones secretas", "secretos" y "tecnologías secretas". ${ }^{3}$ La norma jurídica en cuestión,

2 Título VIII, Código de Defensa Social, 10 de febrero de 1936, Imprenta de la Dirección política de las Fuerzas Armadas Revolucionarias, La Habana, 1969.

3 Resolución 21 del Sistema Nacional de Propiedad Industrial, 7 de enero de 2003, Gaceta Oficial Ordinaria, número 10. 
pese a realizar una distinción entre los diferentes tipos de información, no resultó lo suficientemente clara al determinar el ámbito de protección de los secretos empresariales como institución jurídica.

Por su parte, el Decreto Ley 290 de las Invenciones Dibujos y Modelos Industriales no resolvió el asunto de la regulación de la información secreta susceptible de protección. Uno de los principales beneficios legales que aportó estuvo sobre la base de que respecto a la titularidad en ocasión de la relación jurídico-laboral señala que los derechos y obligaciones previstos subsisten, aun finalizada la relación contractual entre el inventor o autor y la entidad, respecto a la información no divulgada relacionada con la patente o registro. ${ }^{4}$

El Decreto Ley $336^{5}$ De las disposiciones contractuales de Propiedad Industrial en los Negocios Jurídicos, del 10 de agosto de 2018, brinda un nuevo enfoque de lo que se conoce como "secreto industrial", al denominarlo información no divulgada. Solo encierra su círculo de protección en la definición de dicha figura y de la información no divulgada complementaria, además de regular lo relacionado con el contrato de licencia para la utilización de la información no divulgada.

Por su parte, el Decreto Ley $337^{6}$ De la Protección contra las prácticas desleales en materia de Propiedad Industrial, del 10 de agosto de 2018, regula, entre otras cuestiones, lo referente a la protección de la información no divulgada de los actos deshonestos en el mercado. La presente norma jurídica le permite al poseedor de una determinada información no divulgada tener una protección legal en tanto define los actos que constituyen competencia desleal y que se encuentran estrechamente relacionados con dicha institución.

\section{El secreto empresarial. Conceptos}

En el tratamiento normativo de los secretos empresariales es imprescindible establecer un marco de protección y seguridad de la información, es por ello que resulta necesario llegar a una aproximación

\footnotetext{
4 Decreto Ley 290.

5 Decreto Ley 336.

6 Decreto Ley 337.
} 
conceptual. Para una mayor comprensión, se precisa dejar por sentado el significado de los dos vocablos que lo forman: "secreto" y "empresarial".

Se entiende por "secreto" el conocimiento que algunas personas poseen exclusivamente de algo y que cuidadosamente debe ser reservado y oculto. Por tanto, su esencia se basa en no contar ni difundir su contenido, permaneciendo oculto, el cual solo puede ser compartido a aquellas personas que, por su condición, son consideradas apropiadas, es decir, pocas y de absoluta confianza.

El vocablo "empresarial" se encuentra estrechamente vinculado al término "empresa", integrado por un conjunto de componentes que le sirven de base para el logro de un correcto funcionamiento. Cada uno de estos componentes o partes integrantes juegan un rol dentro de esta. Si bien es cierto que existe independencia entre los componentes, estos funcionan como un todo indisoluble en la realización de la actividad empresarial.

El secreto empresarial se usa para referirse a toda aquella información contenida en recetas, fórmulas, prácticas, diseños e investigaciones que no es generalmente conocida ni fácilmente obtenida por el común de las personas, que tiene una utilidad práctica en los negocios y que le otorga a su titular una ventaja sobre la competencia (Tobón Franco, 2009, p. 19).

Los secretos empresariales son todos aquellos conocimientos, informaciones comerciales valiosas, soluciones técnicas y experiencias del saber especializado que no han sido divulgadas, que poseen un valor económico determinado o determinable y que tiene aplicación en el ámbito industrial, comercial y de gestión, por lo que se toman medidas adecuadas para su protección (Aguilar, 2008, p. 7).

Es por ello que se deduce que el secreto empresarial posee un marcado valor económico, puesto que no es conocida dicha información. Por lo general, no se conoce en la actividad empresarial en la que se utiliza, de ahí la categoría de secreto. Puede ser utilizado como actividad empresarial de tipo industrial o comercial. Asimismo, está sometido a un régimen especial a fin de preservar su carácter secreto.

El secreto empresarial puede entenderse que nace de la concepción de una idea, en alguna forma concreta y continua en tanto conserve su carácter de reservado, la cual puede consistir en solucio- 
nes técnicas de índole comercial o ser simplemente conocimiento y experiencia del saber especializado que un industrial o comerciante utiliza en la práctica, sin revelarlo, para la obtención de un producto o un resultado ventajoso (Cruz y Sánchez, 2017, párr. 4).

Un secreto empresarial (también conocido como "secreto industrial") es toda información o conocimiento reservado o confidencial (no divulgado) que posee valor comercial para una empresa (persona o institución). El valor comercial implica que dicha información puede ser susceptible de uso y aprovechamiento o para obtener ventaja competitiva en el contexto de alguna actividad productiva, industrial o comercial (CMS, 2020, párr. 2).

Requiere de una protección especial por ser estos fáciles de copiar, lo cual se entendería como robo de ideas, aspecto este que se regula en las normas que reprimen la competencia desleal. Es de fácil obsolescencia, así como lo es también mantenerlo en secreto. Este secretismo no es extremo, puesto que puede que algunos de sus aspectos sean conocidos por terceros, lo cual no implica que este se haya hecho público.

El secreto empresarial está considerado como un elemento de la propiedad intelectual, en concreto de la propiedad industrial. Sin embargo, a diferencia de las patentes, no se trata de un derecho de exclusividad que deba ser concedido por alguna institución gubernamental para que tenga validez, sino que más bien funciona como un monopolio de facto que perdurará por el tiempo en que la información confidencial o el secreto se mantenga a salvo (CMS, 2020, párr. 3).

Tomando en consideración las conceptualizaciones ofrecidas por los diferentes autores, se define "secreto empresarial" como aquel conjunto de conocimientos e informaciones no accesibles al público en general y que resultan fundamentales para la obtención de un resultado ventajoso, por lo cual constituye una de las formas primordiales que tienen las empresas para proteger dichos conocimientos. Esa información posee un marcado valor económico, lo que hace que sea de gran importancia su protección.

\section{Tipos de secretos empresariales}

Vázquez de Alvaré (2017) afirma que "a los secretos de carácter eco- 
nómico se les han atribuido diferentes denominaciones: secretos comerciales, secretos industriales, know-how, entendiéndose mejor identificarlos como secretos empresariales, por ser un término más abarcador" (p. 13).

Díaz Pérez (2015) sugiere que "el know how y el secreto empresarial son figuras jurídicas que suelen confundirse dentro del tráfico jurídico. Esta confusión se debe principalmente a la ausencia de normas nacionales e internacionales que lo regulen de manera suficiente y sistemática” (párr. 1).

Precisamente por el hecho de que tanto el secreto industrial como el comercial constituyen tipos de secretos empresariales, se hace necesario abordarlos desde las disímiles conceptualizaciones ofrecidas por algunos tratadistas de la materia y de otras afines. En algunas ocasiones se regulan ambas figuras como parte del secreto empresarial.

Cuando lo más relevante era la producción, se estimó que el know how solo estaba referido al secreto sobre conocimientos aplicados a la industria que proporciona una ventaja competitiva. Sin embargo, en la actualidad, la denominación del know how abarca tanto los secretos industriales como los comerciales (Massaguer Fuentes, 1989, p. 20).

Metke Méndez (2001) refiere que "la denominación de secreto empresarial es más acertada que la de secreto industrial, por cuanto abarca no sólo los conocimientos técnico industrial de la empresa sino también los de carácter comercial y financiero" (p. 20).

Una definición tan amplia del secreto comercial busca dar cobijo a los conocimientos técnicos, a la información empresarial y a la información tecnológica, siempre que respecto a estos concurran los requisitos necesarios para su configuración. Dentro de los principales se encuentra el carácter secreto, difícilmente accesible para quienes se dedican a ese sector de actividad tanto a nivel profesional como académico. El carácter reservado le confiera un valor comercial y, por este motivo, se han adoptado medidas para mantenerlo así (Erdozain López, 2016, párr. 8).

Martínez Salcedo (2016) estima que

cuando se hace referencia a los secretos industriales, se señala el conjunto de conocimientos, procedimientos, insumos de producción, técnicas de almacenamiento y preservación, entre otros, que 
un empresario desea mantener oculto por el valor o ventaja competitiva que le significan. (párr. 2)

En sentido amplio, se considera secreto industrial a todo conocimiento relativo a un proceso de fabricación, estrategia de negocio, desarrollo técnico, producto o servicio creado por una empresa, siempre y cuando esta haya tomado las medidas concretas para ocultarlo a sus competidores, por ser garantía de la obtención de una ventaja competitiva frente a ellos. Entre ellas cabe destacar el acceso restringido a dicho secreto a personas que mantengan una relación contractual con la empresa. La fórmula habitual para garantizarlo es el establecimiento de cláusulas de confidencialidad que, por contrato, les obliguen a mantener lo que saben en secreto (CEVIPYME, 2016, párr. 12).

Esta información que debe salvaguardarse en secreto por determinadas cuestiones y que obliga a la persona encargada de mantenerla como tal mediante el contrato de confidencialidad, una vez terminada la relación laboral, podría hacerse pública al no contemplarse en los contratos de trabajo la obligación y el deber del trabajador de mantenerla en silencio. Por esta razón, deben preverse medidas de seguridad una vez que el trabajador decida cambiar de centro laboral, garantizando su resguardo y reserva.

Estos secretos industriales pueden ser principalmente de dos tipos: los concernientes a invenciones o procesos de fabricación que no satisfagan los criterios de patentabilidad (novedad, actividad inventiva y aplicación industrial) y, por consiguiente, puedan protegerse únicamente como secretos industriales, siendo este el caso de las listas de clientes o de procesos de fabricación; y los relativos a invenciones que satisfagan los criterios de patentabilidad y que, a su vez, puedan ser protegidos por patentes. En este caso, la empresa deberá decidir si patenta la invención o si, por el contrario, le da el tratamiento de secreto industrial (Peñaranda Martes, 2017, párr. 11).

El secreto empresarial, como institución jurídica, ofrece disímiles garantías, ya que posibilita la protección de información y conocimientos, así como creaciones que, dado sus características, la ley no regula. Se recomienda proteger a través de secreto industrial cuando la información secreta no es patentable, cuando sea factible mante- 
ner dicha información en secreto durante un período mayor a veinte años (período de validez de la patente), cuando el secreto no se considere de valor tal que amerite ser patentado y cuando se refiera a un proceso de fabricación.

En algunas ocasiones suele emplearse el término "secreto comercial" de forma genérica para referirse al campo de los secretos empresariales. En realidad, el secreto comercial constituye otro tipo de secreto empresarial, el cual comprende todo tipo de información que afecta la vida y naturaleza de la empresa, que tiene valor para esta y que sus competidores querrían conocer (Pomares Carrales, 2017, párr. 4).

Para que sea considerado como tal, la información no puede ser divulgada ni difundida en el círculo donde se manifiesta. Si se hiciera pública, entonces perdería su carácter de secreto y dejaría de ser considerado como tal, a la vez que disiparía su evidente valor.

Sobre la idea de que los secretos comerciales constituyen una forma de propiedad intelectual, se establece que generarían incentivos para la revelación de información en dos formas distintas: en tanto que actúa como sustituto de las inversiones en medidas físicas de preservación de secretos (ocultar una planta de nueva y alta tecnología podría ser físicamente costoso, por lo que el derecho sustituye esa necesidad) y que la existencia del derecho le permita a su titular revelarla para negociar con relación a ella (Rodríguez García, 2016, párr. 30).

Para vender una idea de forma eficiente es esperable que se necesite revelarla, pero esa revelación haría perder la condición de secreto que, precisamente, le da el valor especial. Sin la existencia de una protección legal a esta titularidad, el valor del secreto se pierde; en cambio, con la protección se puede impedir que terceros usen la idea en contravención a la confidencialidad de la relación existente. Ello demuestra la necesidad de protección bajo normas de seguridad de las informaciones que resultan de vital importancia en el funcionamiento de determinada empresa y que generan, para esta última, una ventaja competitiva en el mercado.

La definición y regulación del secreto empresarial es pacífica, uniforme e incluso internacional, pues muchas legislaciones nacionales $y$ tratados internacionales coinciden en la manera de entender este concepto. Sin embargo, no sucede lo mismo en la práctica. Si bien 
los requisitos están delimitados claramente, al alegar la violación de los secretos empresariales se destapa una serie de falencias por parte de los litigantes y empresarios (Sanín Restrepo, 2013, p. 16).

El estudio y análisis de estas categorías conceptuales hace posible considerar que el secreto empresarial posee dos subcategorías: el secreto industrial y el secreto comercial o know how, que regulan la aplicación de dicha información a la industria y lo relacionado con su valor e importancia para el comercio, respectivamente. La denominación de secreto empresarial resulta más acertada respecto a los tipos o subcategorías que lo integran. Dicha institución abarca no solo los conocimientos técnicos industriales de la empresa regulada bajo la tutela del secreto industrial, sino también los de carácter comercial y financiero, los cuales son objeto del secreto comercial.

\section{Requisitos del secreto empresarial}

Para que un conocimiento o información sea considerado secreto empresarial ha de reunir determinados requisitos. Estos deben ser parte de la estrategia que posean las empresas para proteger el capital intelectual, los cuales se resumen a continuación.

El estatus reservado de la información es, de hecho, el pilar básico sobre el que se constituye el sistema de protección de los secretos empresariales, pues su valor se condensa precisamente en ese elemento. El hecho de que esta no sea generalmente conocida origina dos gravísimos inconvenientes: el primero es su indeterminación, ya que quienes sostienen esa aproximación se ven obligados a defender que una información pierde su carácter secreto en un punto intermedio, un tanto difuso, entre el secreto absoluto y su extremo opuesto -esto es, que sea universalmente conocido- y ese extremo, evidentemente, es de difícil determinación (Suñol Buské, 2016, párr. 21).

La regulación del carácter secreto constituye un elemento indispensable, pues en la medida en que sea considerado como tal va a recibir una determinada protección legal, no siendo así cuando se trata de una información conocida por todos o puesta a disposición del público. En este caso, de no poseer tal condición, no sería posible hacer mención del resto de los requisitos que integran dicha institución atendiendo al carácter sine qua non que este posee. 
El segundo elemento que ha de encontrarse presente, estrechamente vinculado al anterior, es que hace reposar el carácter secreto de un conocimiento atendiendo a un juicio numérico que no resulta nada fácil sostener. Lo determinante a estos efectos no es que sea desconocida por un número más o menos reducido de sujetos interesados, sino que sea ignorada y, por tanto, valiosa para alguno de ellos.

El conocimiento de dicha información por un mayor número de persona pone en riesgo el carácter secreto de esta al ser más susceptible de apropiación o actos derivados de la competencia desleal en el mercado. Son varias las razones que confirman esta conclusión, las cuales sostienen que el régimen del secreto empresarial no exige que exista un único titular de la información, sino que, como ocurre con cierta frecuencia, es perfectamente posible que varios empresarios hayan creado independientemente la misma información que, al mantenerse por todos ellos en reserva, permite atribuirle la condición de secreta (Suñol Buské, 2016, párr. 8).

Para el cumplimiento de este requisito no es necesario que la información sea conocida únicamente por su titular, basta con que sea conocida por un número limitado de personas. En ese sentido, Cabanellas de las Cuevas (I984) señala que "no cabe exigir [...] que los conocimientos secretos sólo sean accesibles a su titular, pues ello no sólo va en contravía de la acepción corriente de secreto, sino que impediría la utilización económica de esos conocimientos” (p. 55).

El tercero de los requerimientos del secreto empresarial hace referencia a que esa información debe ser comercialmente valiosa por ser secreta; mantener una determinada información o conocimiento en su ámbito privado le confiere al poseedor una ventaja con respecto a la competencia, siendo un elemento esencialmente subjetivo y que debe valorarse en función del tipo de información en cuestión (Cruz y Sánchez, 2017, párr. 8).

Según Cabanellas de las Cuevas (1984), "el secreto sólo puede recaer sobre información que tenga un verdadero interés para el empresario, en la medida que le da una ventaja competitiva frente a otros empresarios por ser desconocida para éstos” (p. 55).

Dicha ventaja, a decir de Morón Lerma (2012), "puede consistir, en algunas ocasiones, en mejorar el producto o la presentación del mismo, en agilizar los canales de distribución para ofertar el produc- 
to en el mercado lo antes posible o en perfeccionar la planificación interna de la empresa" (párr. 726). Esta se encuentra relacionada de manera directa con la actividad profesional en la que se desarrolla, lo que constituye un elemento fundamental para que este requisito se cumpla.

Por tanto, no basta con que una información sea secreta para que pueda ser protegida por el secreto empresarial, pues es necesario que también sea valiosa para la empresa y otorgue una ventaja a su titular frente a los demás competidores. Dicha ventaja, en algunas ocasiones, puede estar constituida en mejorar el producto o su presentación, como también en agilizar las vías de distribución para ofertar el producto en el mercado lo antes posible o en perfeccionar la organización interna de la empresa.

Como último de los requisitos a tener en cuenta en la configuración del secreto empresarial se encuentra el establecimiento de medidas para mantener la condición de secreta de la información. Para que una información pueda ostentar dicha calificación no es suficiente que sea secreta, sino que también es preciso que su titular haya adoptado medidas que, según las circunstancia del caso, sean razonables para conservar su naturaleza reservada.

Se considera que la apreciación de este requisito exige reconocer ante todo la siguiente idea: existen dos esferas de protección del secreto, una protege el carácter secreto de la información frente a sujetos a los que les ha sido voluntariamente comunicada por su titular o que, en todo caso, la han conocido con la debida autorización; y la otra, la esfera externa, la cual resguarda frente a ataques de terceros que ignoran la información, es decir: frente a espías y otras situaciones similares (Suñol Buské, 2016, párr. 48).

Esta distinción posee una gran importancia en la medida en que muestra que las medidas que se requieren para conservar el secreto han de ser diferentes. Sus titulares deberán limitar el acceso a la información a quienes precisan conocerla, siendo estos los trabajadores, asociados y directivos, quienes se mantendrán bajo el deber de no divulgarla y no utilizarla para un fin diferente de aquel para el que se les comunicó, constituyendo la obligación legal de conservar la información.

Tobón Franco (2009) apunta que "se toman medidas razonables 
cuando se adoptan, de manera consciente, políticas y prácticas suficientes en términos cualitativos o cuantitativos, según las circunstancias, para mantener en secreto la información de que se trate" (p. 19). Estas medidas son de naturaleza diversa y van desde cláusulas de confidencialidad en los contratos laborales hasta sanciones ante la violación o vulneración del secreto.

Se considera secreto empresarial cualquier información o conocimiento, incluido el tecnológico, científico, industrial, comercial, organizativo o financiero que reúna los siguientes requisitos: ser secreto, en el sentido de que, en su conjunto o en la configuración y reunión precisas de sus componentes, no es generalmente conocido por las personas pertenecientes a los círculos en los que normalmente se utilice el tipo de información o conocimiento en cuestión ni fácilmente accesible para ellas; tener un valor empresarial, ya sea real o potencial, precisamente por ser secreto; haber sido objeto de medidas razonable por parte de su titular para mantenerlo en secreto (Sistemius, 2020, párr. 12).

El estudio realizado permite aseverar como principales requisitos del secreto empresarial la configuración de este como reunión precisa de sus componentes, siendo desconocida para personas introducidas en los círculos en los que normalmente se utiliza el tipo de información en cuestión. Otro de los elementos es que posea el carácter secreto de un conocimiento, sea comercialmente valioso por ser secreto así como el establecimiento de medidas para mantener la condición de secreta de la información.

\section{Importancia de la protección del secreto empresarial}

El secreto empresarial constituye una institución cada vez más importante en el ámbito industrial, pues mediante su utilización posibilita a las empresas la protección de determinadas informaciones en las formas antes mencionadas. La preservación del carácter secreto de estos genera per se ventajas competitivas en el mercado para los empresarios, dada la exclusividad de su contenido así como el valor que posee.

Los operadores del derecho, de manera general, conceden especial importancia a la información secreta relativa a cualquiera de los 
ámbitos de la empresa, pues constituye una pieza clave para el éxito empresarial. Esta cuestión, como es evidente, se encuentra íntimamente ligada a la consideración de la propiedad intelectual y, por tanto, también de la información secreta como uno de los motores del desarrollo económico y social (Suñol Buské, 2016, párr. 68).

La protección de estos es un instrumento necesario para el logro de un incentivo general en torno a la actividad científica e investigativa, así como la vía para fomentar la creación de información de valor social y comercial relativa a la empresa. Salvaguardar la información por la vía del secreto empresarial ofrece determinadas ventajas, pues no se precisa que los conocimientos sean totalmente divulgados, exceptuando algunos elementos en el marco de determinadas negociaciones.

Estos carecen de un período limitado de validez legal, pudiendo protegerse indefinidamente mientras permanezca en secreto. No es preciso la solicitud de su registro ni hacer trámite alguno, por lo que tampoco requiere del pago de tasas para mantenerlos vigentes ni se le exige como presupuesto la explotación por parte del titular.

El gran valor que posee el secreto empresarial es que un número muy reducido de personas conocen todos los aspectos de la información de los secretos empresariales de una empresa y que dichos individuos están obligados a mantener una reserva absoluta. En algunos países que se rigen por el derecho consuetudinario o que han aprobado leyes al respecto se puede obtener indemnización por daños y prejuicios por la parte que haya divulgado ilegalmente o que haya obtenido ilegalmente tales secretos empresariales. No obstante, normalmente esas indemnizaciones son mínimas, ya que es imposible obtener una indemnización multimillonaria para estos casos (Moreno Cruz y Horta Herrera, 2007, p. 262).

Resulta de gran importancia la correcta confidencialidad en el momento de conservar un secreto, no solo empresarial, sino de cualquier otro tipo, ya que sin importar el contenido ni el ámbito en el que esté enmarcado todos poseen un gran valor para sus correspondientes titulares. En este sentido, surte el mismo efecto perjudicial al ser divulgado sin la debida autorización, es decir, de forma ilegal.

Otra de las formas y vías en las que se puede hacer valer el secreto empresarial ante su ilegítima divulgación es en el caso de que la tota- 
lidad o la mayoría de las indemnizaciones que se podrían obtener se lograran a través de un arreglo de propiedad. Ello puede efectuarse en forma de embargo de una fábrica o devolución de una propiedad que ha sido obtenida mediante la utilización de la información secreta, comercial e ilegal. Esta propiedad puede ser un bien inmueble, minas o algún otro recurso natural que no hubiera sido descubierto sin el beneficio de la información del secreto empresarial (Moreno Cruz y Horta Herrera, 2007, p. 263).

En cuanto a aquellas informaciones del secreto empresarial que abarcan aspectos de procedimientos biológicos y técnicas de diagnósticos biológicos, entre otros, se pueden prever recompensas por conservar su confidencialidad debido a su carácter valioso, lo cual puede estar enmarcado durante mucho años prediciendo más allá del lapso de vida de cualquier otra forma de protección por patente prevista.

Un secreto empresarial es un elemento esencial que todas las compañías tienen, elemento que le da a esta una ventaja competitiva por sobre cualquier otra, al punto de que esta característica le otorga un valor agregado al producto o servicio que la empresa ofrece. Tal es esa ventaja que el secreto empresarial debe ser resguardado y además amparado jurídicamente para evitar actos que afecten a la competencia de un mercado (Ruiz Fernández, 2015, p. 86).

Los empresarios deben adaptarse a un entorno cada vez más avanzado tecnológicamente, por lo que las medidas de seguridad han de encontrarse estrechamente vinculadas al desarrollo tecnológico. La importancia de que estos se informen sobre la figura del secreto empresarial y lo integren en una estrategia compleja de protección del capital intelectual de la empresa juega un rol fundamental en el mantenimiento del carácter secreto de la información de que se trate.

La elaboración de la estrategia debe ser una amalgama de distintas figuras, como las patentes y los secretos empresariales, que, lejos de ser contradictorias, deben ser vistas como complementarias. La utilización simultánea de varias formas de protección posibilita el sostenimiento del secretismo de dicha institución jurídica, ofreciéndole una mayor protección a la información o conocimiento de que se trate. 


\section{Ventajas y desventajas del secreto empresarial}

La realización de toda actividad en el orden socio-jurídico trae consigo la percepción de un determinado riesgo, que puede ser ventajoso o no. El secreto empresarial como institución jurídica posee rasgos que constituyen verdaderas ventajas en el mercado, sin embargo, en la práctica se generan una serie de situaciones de hecho que lo hacen quedar en desventaja respecto a otras instituciones.

La protección de determinada información por medio de la regulación jurídica que ofrece la figura del secreto empresarial constituye una garantía para los empresarios en el ámbito de desarrollo alcanzado por la industria. La existencia del bloqueo económico, comercial y financiero impuesto por Estados Unidos ha traído como consecuencia que en Cuba se tomen medidas encaminadas a la sustitución de importaciones, elevando el papel del desarrollo de la industria nacional.

El perfeccionamiento del comercio y la industria en Cuba, principalmente la biotecnológica, ha permitido el logro de disímiles resultados en los últimos ańos, dada la labor de destacados investigadores, los cuales, guiados por la elevación de la producción agrícola y la calidad de vida, desarrollan un sinnúmero de productos y procedimientos útiles a tales efectos. La protección de estos por medio de dicha institución legal hace posible la distinción de los productos cubanos del resto de los que existen a nivel internacional, logrando que ingredientes, fórmulas, productos y procedimientos queden protegidos.

La protección de la información por la vía del secreto empresarial ofrece determinadas ventajas, pues no se precisa que los conocimientos sean totalmente divulgados, exceptuando algunos elementos en el marco de determinadas negociaciones. Estos carecen de un período limitado de validez legal, pudiendo protegerse indefinidamente mientras permanezca en secreto. Su configuración no trae consigo la obligación de mantener dicha información o conocimiento en posesión de una determinada persona natural o jurídica durante cierto tiempo.

En el campo de las invenciones, si una de estas no se ha divulgado al público, es considerada secreto empresarial. Una divulgación de ciertos actos que se hallen ocultos puede considerarse ilegal. Estos ejemplos, tomados en cuenta por la Organización Mundial de la Propiedad Intelectual, fundamentan el eficaz complemento a los de- 
rechos de propiedad industrial en los casos de invenciones o signos que no estén protegidos por tal vía (Vázquez de Alvaré, 2017, p. 52).

En cuanto a su registro, este no es necesario, dado que la inscripción registral como requerimiento de forma disipa el carácter secreto de dicha información. Su realización conllevaría a su utilización durante un tiempo determinado, perdiendo de esta manera una de las principales bondades que ofrece la regulación jurídica de dicha institución. La no inscripción genera, a su vez, otra de las ventajas que ofrece su protección y está sobre la base de la no realización del pago de tasas para mantenerlos vigentes.

La identificación de una ventaja específica lleva a la determinación del resto; al no ser objeto de registro y ser protegida dicha información mientras ostente el carácter de secreto, no entrańa para el titular la obligación derivada de su explotación. El poseedor, o quien en su lugar designe, es quien decide poner o no a disposición del público determinada información.

La principal desventaja de la protección del conocimiento mediante secreto es que este llegue a divulgarse o que un tercero, de forma legítima, llegue a los mismos resultados y que, cumpliendo con los requisitos establecidos, decida protegerlo por la vía de patente o sencillamente lo haga de conocimiento público, sin que exista un título legal que lo respalde o proteja, ya que el poseedor no cuenta con el ius prohibendi frente a terceros (Cruz y Sánchez, 2017, párr. 65).

Esta constituye una de las principales vías para que los empresarios pierdan esa valiosa información que les generaba una ventaja competitiva en el mercado.

Es por ello que, en estos casos, quien venía explotando el conocimiento como secreto no tendrá medios legales para impedir la explotación legítima y verá afectada su propia explotación. Ante la ocurrencia de tal problemática, podrá realizarla limitadamente con base en su derecho de uso preexistente cuando este derecho esté legalmente establecido.

La patente es un arma mucho más potente que el secreto empresarial en la solución de conflictos, pudiendo resultar difícil probar que el tercero está usando el secreto, dado que este último puede no encontrarse claramente delimitado, y ello sin revelar el propio secreto. A los efectos de la competencia, resulta más conveniente 
que la protección de los elementos más generales del producto se trate como patente, debido a la posible vulneración de derechos y a la posibilidad de reclamación por parte de su titular. Sin embargo, aquellas informaciones que distinguen un determinado producto o procedimiento del resto en el mercado han de permanecer en secreto bajo la protección de la institución legal en cuestión.

La cuestión de alcanzar el equilibrio entre el secreto empresarial y la patente resulta un elemento difícil en la protección de determinada información. La revelación de más de la información debida en el procedimiento para la concesión de la patente puede provocar la pérdida del carácter secreto; sin embargo, su escasa descripción trae consigo la no aprobación de la patente, dado la insuficiencia de la descripción realizada en la solicitud. Es importante el logro de ese punto intermedio en el que quede protegido el conocimiento secreto y no pierda tal carácter, a la vez que permita el enfrentamiento del titular de la patente ante terceros infractores.

\section{El secreto empresarial en el ámbito digital}

Internacionalmente se reconoce la importancia cada vez mayor de la propiedad intelectual en las economías del nuevo milenio, de carácter digital y basadas en el conocimiento y, muy particularmente, en la disciplina denominada "gestión del conocimiento". La necesidad que se observa cada día de lograr un modelo de desarrollo de base científica y tecnológica resulta más inminente para los países en desarrollo y los menos adelantados, mucho más cuando queda evidenciado el crecimiento exponencial de la brecha tecnológica que separa a los países en vías de desarrollo de los desarrollados (Santos Rivera, 2016, párr. 2).

La propiedad industrial tiene una significación y trascendencia multifacética y multidisciplinaria en el acontecer económico nacional. Involucra todo el quehacer tecnológico, de servicios, de promoción, de publicidad y de comercio por el amplio espectro de categorías o modalidades en las que es susceptible la adquisición de estos derechos, así como por los requisitos que determinan su concesión y por la naturaleza y alcance de estos derechos (Santos Rivera, 2016, párr. 161). 
El registro digital de las informaciones en el ámbito empresarial juega un rol fundamental en el almacenamiento a los efectos de su posterior análisis e identificación de los logros y dificultades de la unidad de que se trate. El archivo de estos conocimientos se realizó en un primer momento sobre medios físicos y, con el desarrollo tecnológico, pasó a ser objeto de los más avanzados medios informáticos, los cuales, pese a su rápido procesamiento de la información, poseen un mayor riesgo de vulneración del contenido recogido en ellos.

Con el internet su empresa puede llegar a nuevos y más amplios mercados en su propio país y en el mundo, cubriendo distancias que sin el Internet tendría que invertir mucho más tiempo y dinero, agilización de las relaciones comerciales con sus clientes en cualquier lugar, disminuyendo los costos en comunicación, promoción permanente de sus productos, servicios e imagen corporativa, 24 horas, 7 días a la semana, 365 días al año. (Patzi Villagrán, 2009, párr. 18)

El paulatino desarrollo de internet podría generar problemáticas respecto al óptimo amparo del secreto empresarial, debido a la gran variedad de prácticas desleales que han salido a la luz en este escenario. Esta red informática progresa a un ritmo acelerado y, con ella, avanza el uso que la sociedad le da, por lo que, en el caso de los secretos empresariales y su presencia en las nuevas tecnologías, las personas involucradas deben mantenerse alertas para poner en práctica sistemas de protección y seguridad que garanticen el correcto desenvolvimiento de la información secreta.

En un principio, el almacenamiento de la información fue dado por sus copias físicas. Normalmente, las compañías reservaban grandes espacios físicos para almacenar toda la información que consideraban importante y debía mantenerse en reserva por un cierto tiempo. Con el advenimiento de las nuevas tecnologías y el computador personal, esta situación no se modificó drásticamente, debido a que solo se permitió la digitalización de esa información (Payan Rodríguez, 2013, párr. 9).

Fue tan solo con el surgimiento de la red mundial de información -internet- que la filtración de la información sometida a reserva co- 
menzó a volverse un real y potencial problema. Las compañías comenzaron a digitalizar toda su información, creando bases de datos digitales y codificados, lo cual a todas luces permitió y posibilitó que las personas o empleados que tuvieran acceso a ellas pudiesen filtrarlas a través de diferentes medios de comunicación. Por ello, las compañías comenzaron a preocuparse por la protección de dicha información (Payan Rodríguez, 2013, párr. 9).

Las empresas, en su mayoría, son portadoras de informaciones, conocimientos, fórmulas y procedimientos que hacen que sus productos y servicios sean únicos en el mercado. La protección del secreto empresarial constituye un elemento fundamental dentro de la empresa, por lo que se recomienda el no almacenamiento de aquellas informaciones o contenido que lo integran en medios informáticos, por el riesgo que posee dicho medio.

Hoy en día, las empresas gastan la mayor parte de su presupuesto en tecnología basada en sistemas de almacenamiento, en los que se registran el flujo de capital, productos y personas de la compañía, lo que posibilita de una forma más rápida y voluminosa la filtración de la información. Los dispositivos móviles de última tecnología permiten la comunicación instantánea, que es otro de los mecanismos a partir de los cuales se puede filtrar la información (Payan Rodríguez, 2013, párr. 10).

Estudios demoscópicos recientes apuntan a que los empresarios consideran sus secretos empresariales importantes para el crecimiento, la competitividad y el comportamiento de su negocio en materia de innovación. Los sectores de actividad que otorgarían mayor importancia a la protección de sus secretos empresariales son aquellos que realizan una fuerte inversión. Estos mismos sectores considerarían que, a menudo, el régimen jurídico de protección del secreto empresarial es un mecanismo de recuperación de la inversión más efectivo que la patente de invención u otros mecanismos legales de protección (Estrada Cuadras, 2017, p. 36).

En cuanto al almacenamiento de informaciones que resulten de carácter secreto, han de tomarse las medidas de seguridad y protección para evitar que puedan ser obtenidas por medios ilícitos, afectando de esta manera tal carácter. Entre las principales medidas se observan: el establecimiento de contraseñas y protección de correos 
electrónicos y activación de antivirus, así como la realización de copias de seguridad protegidas de igual modo.

Cuba, al encontrarse inmersa en el proceso de perfeccionamiento del sistema empresarial de conjunto con la informatización de la sociedad, debe extremar las medidas en aras de proteger los secretos empresariales que son guardados en medios digitales. El proceso de informatización trasluce la necesidad objetiva de la creación de una norma que proteja la institución en sus más amplias dimensiones, con un alcance general dirigido no solo a los medios físicos, sino también a los digitales, que ganan cada vez un mayor espacio en el sector empresarial.

\section{Regulación jurídica del secreto empresarial en América Central}

La figura del secreto empresarial ha sido legalmente reconocida por la mayoría de los Estados a nivel internacional, dada la importancia que posee la protección de determinadas informaciones en el ámbito empresarial y comercial. América Central no ha sido la excepción, dado que en las legislaciones de la mayoría de los países que la integran se le brinda especial protección.

En Guatemala, la Ley 57 de 2000, en su artículo 147, reconoce la existencia del secreto empresarial como aquella información que tiene un valor comercial por el hecho de que su propietario la mantiene reservada, siempre que no sea una reunión precisa de sus componentes ni de fácil acceso para personas que se encuentran en los círculos en los que normalmente se utiliza ese tipo de información. ${ }^{7}$ Esta definición se asemeja a los aspectos doctrinales analizados anteriormente $y$, desde su propia conceptualización, señala el valor comercial que ha de estar presente, dando lugar en este sentido a la denominación "secreto comercial".

Uno de los países que no regula legalmente la protección de los secretos empresariales y comerciales es Belice, donde la incipiente legislación en materia de derecho de autor y derechos conexos no se pronuncia sobre la protección de la información de valor, por lo que

7 Ley número 57 de 2000, Guatemala, artículo 147. https://www.wipo.int/ edocs/lexdocs/laws/es/gt/gt001es.pdf. 
en ese sentido existe una ausencia de regulación en su normativa. Los empresarios quedan en un estado de total desprotección en la medida en que este país no posea normas que repriman los actos deshonestos en el mercado en relación con dicha institución jurídica.

En Honduras, la ley previene un capítulo único para normar lo relativo a los secretos industriales, estableciendo en primer término una definición: "Se considerará como secreto industrial cualquier información no divulgada que una persona natural o jurídica posea, que pueda usarse en alguna actividad productiva, industrial o comercial, y que sea susceptible de transmitirse a un tercero" (Font Acuña, 2014, p. 203).

Un elemento que distingue la regulación jurídica de esta institución en Honduras del resto de los países de la región es precisamente la posibilidad de transmisión de la información no divulgada. En su conceptualización solo hace referencia a la utilidad de esta en la realización de una determinada actividad sin narrar el necesario valor y la ventaja que debe representar dicho secreto.

En El Salvador, el Decreto 604 Ley de Propiedad Intelectual, en su artículo 177, considera secreto industrial o comercial toda información que tenga valor comercial de aplicación industrial o comercial, incluyendo la agricultura, la ganadería, la pesca y las industrias de extracción, transformación y construcción, así como toda clase de servicios que guarde una persona con carácter confidencial, que le signifique obtener o mantener una ventaja competitiva o económica frente a terceros, en la realización de actividades económicas y respecto a la cual haya adoptado los medios o sistemas razonables para preservar su confidencialidad y el acceso restringido a ella. ${ }^{8}$

En Nicaragua, el Decreto 88 de 2001, Reglamento de la Ley de Patentes de Invención, Modelos de Utilidad y Diseños Industriales, en su artículo 55 regula que los secretos empresariales se protegen indefinidamente y deberán reunir los siguientes elementos: ser secretos en el sentido de que no sean como cuerpo o en la configuración o reunión precisa de sus componentes, generalmente conocidos, ni fá-

8 Decreto 604, Ley de Propiedad Intelectual, artículo 177. http://www.transparenciafiscal.gob.sv/downloads/pdf/DC5111_30_Ley_de_Propiedad_Intelectual.pdf. 
cilmente accesibles para personas introducidas en los círculos en los que normalmente se utiliza el tipo de información en cuestión; tener un valor comercial por ser secretos y haber sido objeto de medidas razonables tomadas por la persona que legítimamente la controla para mantener el secreto.

Costa Rica regula en el Reglamento a la Ley de Información no divulgada elementos de especial interés en cuanto a la protección legal de dicha institución jurídica que fundamentan o dan un mayor tratamiento a las figuras que la legislación sustantiva establece. En el artículo 2 reglamenta el ámbito de protección de la información no divulgada referente a los secretos comerciales e industriales o a los secretos empresariales de carácter comercial. ${ }^{9}$ Tal definición trasluce la necesidad de existencia de un marcado valor para el comercio de la información que ha de permanecer secreta.

En Panamá se encuentra regulado jurídicamente el secreto empresarial en la Ley 35 de Disposiciones sobre la Propiedad Industrial. En el artículo 83 del propio cuerpo legal queda definido como "secreto industrial o comercial" toda información de aplicación industrial o comercial que, con carácter confidencial, guarde una persona natural o jurídica, que le signifique obtener o mantener ventaja competitiva o económica frente a terceros en la realización de actividades económicas y respecto a la cual haya adoptado los medios o sistemas suficientes para preservar su confidencialidad y su acceso restringido. ${ }^{10}$

El estudio y análisis del secreto empresarial como institución jurídica en la región permite conocer que en la mayoría de los países que la integran existe una legislación sustantiva en materia de protección de la propiedad industrial. Belice constituye una excepción, en la medida en que no se encuentra regulada la protección de este, lo que deviene en perjuicio de los empresarios que decidan mantener los conocimientos de valor bajo la tutela jurídica, no encontrando protección a tales efectos.

9 Reglamento a la Ley de Información no Divulgada, 2000. http://www.pgrweb.go.cr/scij/Busqueda/Normativa/Normas/nrm_texto_completo.aspx?param 1=NRTC\&nValor1 = 1 \&nValor2=41810\&nValor3=74709\&strTip$\mathrm{M}=\mathrm{TC}$.

10 Ley 35 de Disposiciones sobre la Propiedad Industrial (LPI), artículo 83, 2008. http://www.sice.oas.org/int_prop/nat_leg/Panama/D7a.asp. 
El desarrollo de la ciencia, la técnica y, con ello, la industria ha sido el escenario propicio para la gestación de normas que protejan las instituciones que integran la propiedad intelectual de manera general y el secreto empresarial de forma particular. La protección de los derechos derivados del intelecto humano hoy juegan un rol fundamental en el desarrollo de la humanidad y requieren cada vez más del amparo de normas que salvaguarden las creaciones de los titulares ante terceros.

La regulación jurídica de los derechos derivados del secreto empresarial en los países anteriormente mencionados divisa la necesaria implementación de una normativa en Cuba que regule de forma especial la institución. Los productos y procedimientos cubanos ganan cada vez un mayor espacio en el mercado debido a las características que poseen, motivo que los convierte en únicos, por lo que resulta necesaria una norma que salvaguarde la información secreta que hace posible dicha peculiaridad y valor en el mercado.

\section{Regulación del secreto empresarial en el ordenamiento jurídico cubano}

En el ámbito de la propiedad industrial, el ordenamiento jurídico cubano se encuentra ante importantes desafíos en aras de ajustar la legislación interna a las experiencias internacionales más novedosas. En cuanto a materia de secretos empresariales, deberán preverse estrategias de protección y seguridad de la información en todos los niveles de la empresa, ya que la mayoría de las entidades nacionales desconocen la utilidad de esta institución.

Existe una figura cuya naturaleza no se identifica con la de los secretos empresariales, instituida como "informaciones oficiales". Estas informaciones, en ciertas ocasiones, son consideradas secretos, lo cual implica la protección de un conocimiento cuya revelación no autorizada puede causar perjuicios en la esfera política, militar, científica, económica, técnica, cultural, social o cualquier otra de importancia para el funcionamiento del Estado.

Los secretos empresariales son, en su mayoría, informaciones o conocimientos con un valor económico significativo, por lo que en determinados momentos pueden llegar a tener significación como 
información oficial clasificada. Los secretos estatales, vinculados directamente con las informaciones clasificadas, cuentan con una protección específica y encuentran respaldo en la vía penal, por lo que por su connotación no se identifican con el tipo de protección que se le debe conferir a los secretos empresariales.

A partir de la década de 1990, han sido muchos los cambios llevados a cabo en la economía cubana que han propiciado la aparición de nuevos operadores económicos, la creación de espacios de competencia comercial y de determinados actos de competencia desleal. Entre esos cambios cabe mencionar las reformas constitucionales en cuanto al régimen de propiedad y a la descentralización del comercio exterior; la despenalización de la tenencia de divisas por parte de la población; las transformaciones estructurales en la agricultura, así como el espacio concedido a la inversión extranjera con la actividad comercial autorizada por la Ley 118, Ley de la Inversión Extranjera. ${ }^{11}$

Con respecto a la protección que se les debe brindar, se estipula en los Acuerdos sobre los Aspectos de los Derechos de Propiedad Intelectual relacionados con el Comercio (ADPIC) que tanto los secretos empresariales como la protección contra la competencia desleal se deben proteger por la misma vía. En Cuba existen deficiencias en cuanto a la protección del secreto empresarial, por lo cual es necesario remitirse a la ley civil o penal con el fin de ofrecer cierto amparo frente a sus posibles divulgaciones.

En cuanto al ámbito del derecho penal, en el Título V Delitos contra la Economía Nacional se halla el Capítulo VII, el cual regula en el artículo 226 el delito de difusión ilegal y de uso no autorizado de inventos, ${ }^{12}$ en el que el bien jurídico protegido es la economía nacional y no la propiedad industrial. Se emplea el término "invento”, pero no se dice qué es lo que se entiende por tal o bien si está asociado a las informaciones secretas; cierto es que excluye de la protección a un grupo importante de conocimientos o informaciones que pueden tener valor económico o comercial para la empresa sin ser considerados como tal.

11 Ley 118 De la Inversión Extranjera, 16 de abril de 2014, Gaceta Oficial Extraordinaria, número 20.

12 Ley 62. 
Según Valdéz Díaz (2006),

en el caso de la vía civil resultan de aplicación los preceptos del Código referentes a la responsabilidad civil por actos ilícitos, en función del carácter supletorio del Código Civil establecido en la Disposición Final Primera y el Artículo 8 del propio cuerpo legal. (p. 189)

Se pone de manifiesto la existencia de un daño o perjuicio ilícitamente causado al poseedor del secreto empresarial por un tercero, el cual quedará obligado a resarcir al primero mediante la indemnización, siendo esta la única forma de resarcimiento de las que regula que resultará aplicable en dicho caso.

El hecho de provocarle a una determinada persona un daño genera per se la obligación de resarcirlo en correspondencia con las diferentes reglas que la ley prevé para hacer efectiva dicha indemnización ante el daño ocasionado por un tercero. Gracias a la definición tan general dada en el artículo $81,{ }^{13}$ puede aplicarse a la figura en cuestión, puesto que al existir una infracción al deber de confidencialidad sobre determinados conocimientos, informaciones o experiencias secretas se le ocasiona a su poseedor legítimo o titular un grave perjuicio.

El secreto empresarial, por sus características y necesidad de protección, constituye una institución jurídica que no solo queda regulada en el ámbito civil y penal, sino que encuentra su tutela legal en otras ramas del derecho, como lo es derecho laboral. Su regulación en este ámbito se considera un elemento de vital importancia en la medida en que permite mantener oculta dicha información, evitando que las personas que la manejan o de algún modo tienen contacto directo con ella no puedan hacerla de uso público, ni ponerla a disposición de un tercero no vinculado a la activad en torno al secreto ni apto para conocer su existencia.

Los contratos de confidencialidad deben ser aplicados para salvaguardar los intereses actuales y perspectivos de las entidades. Medidas adecuadas y oportunas deben ser introducidas para garantizar

13 Ley 59. 
que las actividades que conlleven la divulgación y promoción comercial, la exhibición en ferias, exposiciones y eventos, contactos e intercambios personales, comunicaciones orales, transferencia de documentos y visitas o el traslado de trabajadores provoquen la pérdida del carácter secreto de la información no divulgada (Santos Rivera, 2016, p. 30).

Lo analizado hasta el momento indica que son muy diversos los caminos que hay para proteger los secretos empresariales, sin embargo, no puede existir conformidad respecto al hecho de no contar con un cuerpo legal debidamente estructurado que regule lo concerniente a esta cuestión. Por la importancia del tema, es necesario establecer mecanismos que garanticen la plena protección de los secretos empresariales valiosos. En referencia a lo antes expuesto, se considera que es necesaria la existencia de una norma sustantiva en materia de secreto empresarial como parte de la propiedad industrial mediante normas de remisión a la legislación civil, penal y laboral.

\section{Propuesta de lege ferenda sobre el secreto empresarial en el ordenamiento jurídico cubano}

El desarrollo socioeconómico acrecentado en las últimas décadas en Cuba y el surgimiento de nuevas formas de propiedad, así como el perfeccionamiento alcanzado por el sector empresarial, han puesto de relieve la ineludible protección de la Propiedad Industrial. La necesidad de sustitución de importaciones en el país ha incidido favorablemente en la elevación del papel de la investigación científica como elemento trascendental en las ramas del desarrollo sobre la base del perfeccionamiento empresarial.

El proceso de actualización del modelo económico en el país tiene como uno de sus ejes transversales el desarrollo de la empresa en la producción de bienes y servicios, en los que esta constituye la mayor fuente generadora de creaciones industriales. Estas creaciones pueden ser protegidas por las diferentes modalidades de la propiedad industrial, entre ellas, invenciones por medio de patentes así como secreto empresarial.

Como resultado de la implementación de nuevas políticas puestas en práctica por el Gobierno, es promulgado el Decreto Ley 336 
De las disposiciones contractuales de Propiedad Industrial en los negocios jurídicos. ${ }^{14}$ Este cuerpo legal per se trasluce el logro de un desarrollo industrial sostenible, el cual requiere de capacidades tecnológicas propias, como también la adquisición de tecnología en el proceso de inversión nacional y extranjera, mediante la concertación de contratos que incluyan disposiciones sobre propiedad industrial que aseguren el pleno acceso a la tecnología así como el desarrollo comercial que se atempere a la realidad existente.

Este decreto ley ofrece un nuevo enfoque del secreto empresarial al definirlo en su artículo $3^{15}$ como "información no divulgada", término que, a consideración del autor, abarca mucho más que esa determinada información o fórmula de carácter secreto, dejando abierto el diapasón a la interpretación del operador del derecho. La idea que se persigue se sienta sobre la base de la unificación de los diferentes tipos que integran el secreto empresarial. En este no se logra definir claramente la integración tanto del secreto industrial como del comercial en una sola figura.

Cuando se hace referencia a esa información que no se ha divulgado, podría confundirse con el período de vigencia de cualquiera de las formas en las que se manifiestan las creaciones industriales. Durante esa etapa, las invenciones no se encuentran a disposición del público, por ende, están secretas o no divulgadas, llegando a la conclusión de que la nueva denominación da lugar a posibles confusiones a la hora de definir correctamente dicha institución legal.

El concepto de "secreto comercial" sigue la estela que respecto a la definición de "información no divulgada" hace el Acuerdo sobre los Aspectos de los Derechos de Propiedad Intelectual relacionados

14 Decreto Ley 336.

15 Información no divulgada: información que, como cuerpo o en la configuración y reunión precisas de sus componentes, no es generalmente conocida ni fácilmente accesible al público y es objeto de medidas razonables para mantenerla en esas condiciones, lo que hace que tenga un valor comercial. Esta comprende el conjunto de conocimientos, saberes, instrucciones, planos, esquemas, especificaciones, entre otros, que han sido creados, desarrollados o se poseen legítimamente por la persona natural o jurídica que los controla y que se conservan en régimen de confidencialidad, Decreto Ley 336, artículo 3 inciso a). 
con el Comercio, firmado en Marrakech el 15 de abril de 1994. Según este texto internacional, los Estados firmantes deberán proteger toda información no divulgada de las empresas y organismos, entendiendo por esta aquella que es secreta, en el sentido de que no sea conocida ni de fácil acceso por quienes se mueven en los círculos en los que normalmente se utiliza la información no divulgada (Molins Fernández, 2017, párr. 8).

Aparece una nueva figura accesoria a la anteriormente mencionada, la cual queda definida en el propio cuerpo legal como información no divulgada complementaria, ${ }^{16}$ quedando separada de manera especial de la anterior institución, la cual se ciñe a normar de manera expresa los requisitos que ha de tener el secreto empresarial en sí. Por su parte, la existencia de esta resulta necesaria para el desarrollo y explotación productiva y comercial del producto o procedimiento objeto de protección.

El Decreto 343 del Consejo de Ministros ${ }^{17}$ hace referencia a la Organización Mundial del Comercio, de la cual Cuba es parte y, por ende, adhiere al Acuerdo sobre los Aspectos de los Derechos de Propiedad Intelectual relacionados con el comercio. A partir de la ratificación por parte del Estado cubano del acuerdo antes mencionado, incorpora disposiciones que permiten asegurar una protección eficaz contra las prácticas desleales en la industria y el comercio en materia de propiedad industrial.

Otro de los elementos referidos a la protección de las informaciones y conocimientos de carácter oculto está dado por su denominación de información no divulgada tal y como lo define el propio cuerpo legal. Esta información debe encontrarse legítimamente bajo el control de personas naturales y jurídicas y determinados los datos de prueba depositados en las autoridades reguladoras que aprueban la comercialización de productos, fundamentalmente en las esferas referidas en dicho texto, entre ellas, la farmacéutica o de químicos agrícolas que utilizan nuevas entidades químicas.

El propio decreto resulta lo suficientemente claro al definir como uno de los principios fundamentales del sistema de propiedad in-

16 Inciso a) del Decreto Ley 336, artículo 3.

17 Decreto 343. 
dustrial asegurar la protección, gestión y comercialización de los derechos de propiedad industrial y de la información no divulgada. ${ }^{18}$ De la regulación jurídica de la información divulgada como principio elemental de la propiedad intelectual se abre una brecha hacia la necesidad de regulación de la institución jurídica en una norma independiente, en la que se reglamenten los aspectos generales en torno a su tutela legal.

En lo referente a los actos deshonestos que puedan generarse en la obtención de información no divulgada, aparece una nueva norma que regula de manera especial lo concerniente al tema. El Decreto Ley 337 De la Protección contra las prácticas desleales en materia de Propiedad Industrial ${ }^{19}$ aborda desde una nueva óptica la regulación de la competencia desleal en el ordenamiento jurídico cubano. La norma en cuestión resulta garante de los derechos exigidos por aquellos individuos que les son vulnerados ilícitamente sus derechos derivados de creaciones del intelecto.

La inclusión de la denominación de información no divulgada como sujeto pasivo en los distintos actos o conductas desleales que pueden tener lugar en el mercado constituye un paso de avance en cuanto a la protección jurídica de la figura. Si bien la protección de la competencia desleal como institución jurídica se halla estrechamente vinculada a la información no divulgada, requiere de una normativa que la regule en todas sus dimensiones y no como parte de la primera.

El artículo 3.120 del propio cuerpo legal se refiere a las condiciones que han de estar presentes en determinada información para que sea considerada información no divulgada. En primer lugar, es aquella en la que como cuerpo o en la configuración y reunión precisas de sus componentes no sea generalmente conocida ni fácilmente accesible para personas introducidas en los círculos en que normalmente se utiliza el tipo de información en cuestión.

La segunda cuestión a tener en cuenta es la referida a la existencia de un valor comercial por no haber sido accesible al público por

\footnotetext{
18 Decreto 343, artículo 2.

19 Decreto Ley 337.

20 Decreto Ley 337, artículo 3.1.
} 
cualquier medio, siendo objeto de medidas razonables tomadas por la persona que legítimamente la controla. Este elemento hace referencia de manera tácita al necesario control sobre dicha información referida a las cláusulas de confidencialidad u otras medidas en torno a su protección.

El último de los elementos o requerimientos a los que se refiere la propia norma es que exista constancia de estos conocimientos e informaciones en documentos, medios electrónicos, magnéticos y otros. Al establecer el precepto planteado anteriormente, resulta esencial la toma de medidas extremas en aras de mantener el carácter oculto de la información.

Un aspecto novedoso que se incorpora en el texto de la propia norma está relacionado con la revelación o uso no autorizado de la información no divulgada. En lo referente a la ocurrencia de tales situaciones de hecho, queda sujeto a la reclamación por parte de las personas debidamente legitimadas en defensa de sus derechos.

En el artículo 4 se define como "práctica desleal" en materia de propiedad industrial la divulgación a terceros o la adquisición o utilización por terceros de información no divulgada sin el consentimiento de las personas naturales y jurídicas que la tienen legítimamente bajo su control, siempre que sea de manera contraria a los usos comerciales honestos. ${ }^{21} \mathrm{La}$ inclusión de la figura como acto deshonesto constituye un elemento fundamental en la protección legal de esta ante vulneraciones o afectaciones por parte de terceros.

En la realidad cubana actual predomina la orfandad normativa del secreto empresarial en cuanto a la Propiedad Intelectual, lo que entorpece el funcionamiento y la calidad de las leyes nacionales en esta materia. Frente a la posible ocurrencia de infracciones relacionadas con la exposición de los secretos empresariales, los tribunales competentes sancionan leyes adjetivas en dependencia del delito cometido, con la repercusión que trae consigo en las distintas áreas del derecho ante la insuficiente reglamentación legislativa que vive el país y frente a la inexistencia de respuestas legales específicas y eficaces.

El análisis de las regulaciones para la implementación del sistema

21 Decreto Ley 337, artículo 4. 
interno de la propiedad industrial en relación con los secretos empresariales asevera que existen imprecisiones en la tutela legal que se le ofrece a esta. Se puede señalar el empleo de más de una terminología, cuestión que conlleva la presencia de dilemas y propicia dudas lamentables. La inclusión de artículos que contengan aspectos específicos del secreto empresarial en el ordenamiento jurídico cubano, en el que se regulen de manera clara y precisa en qué consiste, cuáles son los objetos de protección, los requisitos para su constitución y los tipos de secretos empresariales, así como los derechos que ostentan el o los titulares del secreto empresarial, permitiendo la comprensión de aspectos distintivos ausentes en el ordenamiento jurídico cubano, es una exigencia que traerá consigo cambios sustanciales en el mercado.

Por la ineludible inclusión de la normativa en materia de derechos de propiedad industrial referente al secreto empresarial, y a raíz de la deficiente protección existente en la legislación nacional, se propone la redacción de la siguiente normativa.

CAPÍTULO---: Del secreto empresarial.

Disposiciones Generales

ARTíCULO---: el secreto empresarial es aquel conjunto de conocimientos e informaciones no accesibles al público en general y que resulta fundamental para la obtención de un resultado ventajoso, por lo cual constituye una de las formas primordiales que tienen las empresas para proteger dichos conocimientos. Esta información posee un marcado valor económico, lo que hace que sea de gran importancia su protección.

ARTÍCULO---: deberán ser objeto de protección por parte del secreto empresarial las invenciones, los modelos industriales y dibujos, con especial mención de los artículos de moda, singularmente los vestidos, las prácticas manuales, las innovaciones que sirven para obtener el máximo rendimiento de procesos y objetos industriales, sean o no patentables, así como los secretos comerciales relativos al sector puramente comercial de la empresa, como las listas de clientes, listas de proveedores y cálculos de precios.

ARTÍCULO---: los requisitos que deberán estar presentes para la conformación del secreto empresarial serán: 
a) Ser secretos en el sentido de que no sea, como cuerpo o en la configuración y reunión precisas de sus componentes, totalmente desconocida ni fácilmente accesible para personas introducidas en los círculos en los que normalmente se utiliza el tipo de información en cuestión.

b) Poseer carácter secreto.

c) Ser comercialmente valioso.

d) Ostentar medidas para mantener la condición de secreta de la información.

ARTÍCULO---: los secretos empresariales, al constituir aspectos reservados del empresario, engloban dos especies: el secreto industrial y el secreto comercial.

ARTÍCULO---: el titular del secreto empresarial puede prohibir los actos ilícitos de obtención y de utilización o revelación del secreto.

a) La obtención ilícita tendrá lugar cuando se haga sin consentimiento del titular mediante el acceso, apropiación o copia no autorizadas de documentos, objetos, materiales, sustancias, ficheros electrónicos u otros soportes que contengan el secreto empresarial o a partir de los cuales este se pueda deducir o por cualquier otra actuación que, en las circunstancias del caso, se considere contraria a las prácticas comerciales leales.

b) A su vez, la utilización o revelación ilícita del secreto tendrá lugar cuando se haga sin el consentimiento del titular y la lleve a cabo quien haya obtenido el secreto empresarial de forma ilícita, quien haya incumplido un acuerdo de confidencialidad o cualquier otra obligación de no revelar el secreto empresarial o quien haya incumplido una obligación contractual o de cualquier otra índole que limite la utilización del secreto empresarial.

El hecho de mantener una determinada información bajo la tutela del secreto empresarial genera para los empresarios un gran número de ventajas, como también desventajas. La incursión empresarial en el ámbito digital ha dado lugar a una mayor vulnerabilidad de apropiación de las informaciones no conocidas, lo cual requiere de soluciones técnicas que posibiliten su máxima protección. Es preciso conformar un adecuado marco teórico de la figura de los secretos empresariales y generar esfuerzos encaminados a establecer su correcta protección. 


\section{Conclusiones}

El secreto empresarial es aquel conjunto de conocimientos e informaciones no accesibles al público en general y que resulta fundamental para la obtención de un resultado ventajoso, por lo cual constituye una de las formas primordiales que tienen las empresas para proteger dichos conocimientos. Esa información posee un marcado valor económico, lo que hace que sea de gran importancia su protección.

El hecho de mantener una determinada información bajo la tutela del secreto empresarial genera para los empresarios un gran número de ventajas y desventajas. La incursión empresarial en el ámbito digital ha dado lugar a una mayor vulnerabilidad de apropiación de las informaciones no conocidas, lo cual requiere de soluciones técnicas que posibiliten su máxima protección. Es preciso conformar un adecuado marco teórico de la figura de los secretos empresariales y generar esfuerzos encaminados a establecer su correcta protección.

En Cuba, la protección legal del secreto empresarial es insuficiente, quedando desprotegidos los derechos de los empresarios poseedores de informaciones secretas. Esto genera problemáticas y desmotivación entre ellos, ya que aún no existe una legislación que regule de forma amplia el contenido referente al tema.

Resulta necesaria la inclusión de los principales presupuestos teórico-doctrinales del secreto empresarial en el ordenamiento jurídico cubano, como su concepto, objetos de protección, requisitos, clasificaciones y derechos de sus titulares, lo cual propiciaría su adecuado tratamiento jurídico y sería un gran avance en la protección legal del sector empresarial.

\section{Bibliografía}

Aguilar Villán, A. (2008). Los Secretos Empresariales en la Propiedad Industrial. Valoración en el contexto cubano (Tesis presentada en opción del grado científico de Doctor en Ciencias Jurídicas). Universidad de La Habana, Ciudad de la Habana.

Cabanellas de las Cuevas, G. (1984). Régimen jurídico de los conocimientos técnicos.

Know How y secretos comerciales e industriales. Editorial Heliasta.

CEVIPYME. (2016). Qué es, cómo usar y para qué sirve el secreto industrial. ht- 
tps://cevipyme-wordpress-com.cdn.ampproject.org/v/s/cevipyme.wordpress. com/2016/06/14/que-es-como-usar-y-para-que-sirve-el-secreto-industrial/ $\mathrm{amp} /$ ?amp_js_v=a6\&amp_gsa $=1 \& u s q p=m q 331 \mathrm{AQKKAFQArABIIA-}$ CAw\%3D\%3D\#aoh=16393382588970\&referrer=https\%3A\%2F\%2Fwww. google.com\&amp_tf=De\%20\%251\%24s\&ampshare=https\%3A\%2F\%2 Fcevipyme.wordpress.com $\% 2$ F $2016 \% 2$ F06\%2F 14\%2Fque-es-como-usar-y-para-que-sirve-el-secreto-industrial $\% 2 \mathrm{Famp} \% 2 \mathrm{~F} \% 23$ aoh $\%$ 3D16393382588970\%26referrer\%3Dhttps\%253A\%252F\%252Fwww.google.com\%26amp_tf\%3DDe\%2520\%25251\%2524s.

CMS (2020). Guia de Secretos Empresariales o Industriales. CMS Law. https://cms. law/es/per/sobre-cms/about-us.

Cruz Labrada, O. y Sánchez Merino F. (2017). El Secreto Comercial en Cuba, un breve acercamiento. https://www.monografias.com/trabajos96/secreto-comercial-cuba-breve-acercamiento/secreto-comercial-cuba-breve-acercamiento. shtml.

Díaz Pérez, G. (2015). La protección jurídica del know how y el secreto industrial en el Derecho Español (Tesis presentada en opción a la Titulación de Máster en Propiedad Intelectual y Derecho de las nuevas tecnologías). Universidad Internacional de la Rioja, Bogotá. https://reunir.unir.net/handle/123456789/4469.

Erdozain López, J. (2016). Comentario a la nueva Directiva (UE) 2017/943, sobre Secretos Comerciales. http://noticias.juridicas.com/conocimiento/articulos-doctrinales/11313-comentario-a-la-nueva-directiva-ue-2016-943-sobre-secretos-comerciales/.

Estrada Cuadras, A. (2017). El secreto empresarial. Una perspectiva jurídico-penal. Editorial Bosch.

Font Acuña, T. (2015). Requisitos que determinan la protección jurídica del secreto empresarial. http://servicio.bc.uc.edu.ve/derecho/revista/idc37/art08.pdf.

Martínez Salcedo, J. (2016). Qué es un secreto empresarial. https://www.asuntoslegales.com.co/consultorio/el-secreto-empresarial-2386466.

Massaguer Fuentes, J. (1989). El contrato de licencia de know-how. Editorial Bosch.

Metke Méndez, R. (2001). Lecciones de Propiedad Industrial (Tomo I). Editorial Diké.

Molins Fernández, F. (2017). La protección del Secreto Comercial. Lleytons. International Private Law. https://www.lleytons.com/wp-content/uploads/2017/07/ La-proteccio\%CC\%81n-del-secreto-comercial_FM.pdf.

Moreno Cruz, M. y Horta Herrera, E. (2007). Selección de lecturas de Propiedad Industrial. Editorial Félix Varela.

Morón Lerma, E. (2012). La tutela penal del secreto de empresarial, desde una teoria general del bien jurídico. https://www.tesisenred.net/bitstream/handle $/ 10803 / 5066 /$ eml4de 5 .pdf? sequence $=4$.

Patzi Villagrán, E. (2009). Hablemos de Internet, su alcance y su desarrollo. http:// edgarpatzi.blogspot.com/2009/02/hablemos-de-internet-su-alcance-y-su.ht$\mathrm{ml} ? \mathrm{~m}=1$. 
Payan Rodríguez, C. (2013). Secreto empresarial, vigencia como mecanismo de protección en la Propiedad Intelectual. https://revistas.uexternado.edu.co/index. php/propin/article/view/3006/3656.

Peńaranda Martes, A. (2017). El secreto industrial como mecanismo de protección de la Propiedad Intelectual. Asuntos Legales. https://www.asuntoslegales.com.co/actualidad/el-secreto-industrial-como-mecanismo-de-protección-de-la-Propiedad-Intelectual-2006914.

Pomares Carrales, M. (2017). El secreto empresarial: concepto, tipos y protección. https://www.euroresidentes.com/empresa/derecho-mercantil/el-secreto-empresarial-concepto-tipos-y-proteccion.

Rodríguez García, G. (2016). Dueño de tus silencios, esclavo de tus palabras: Reflexiones sobre la protección legal de los secretos comerciales. http://revistas.pucp. edu.pe/index.php/forojurídico/article/viewFile/13773/14397.

Ruiz Fernández, M. (2015). La protección jurídica del secreto empresarial como elemento constitutivo de la libre competencia en el Ecuador. https://rraae.cedia.edu. ec/Author/Home?author=Ruiz+Fern\%C3\%A1ndez\%2C+Mario.

Sánchez Merino, F. (2017). El Secreto Comercial en Cuba, un breve acercamiento. https://www.monografias.com/trabajos96/secreto-comercial-cuba-breve-acercamiento/secreto-comercial-cuba-breve-acercamiento.shtml.

Sanín Restrepo, J. (2013). El secreto empresarial: Concepto teórico y fallas a la hora de alegar su violación ante la superintendencia de industria y comercio. Revista de Derecho Privado, 49, 1-34.

Santos Rivera, A. (2000). La Propiedad Industrial como mecanismo de contrainteligencia empresarial. Taller Internacional de Inteligencia empresarial y Gestión del Conocimiento en la Empresa (IntEmpres'2000). Instituto de Información Científica y Tecnológica (IDICT), Ministerio de Ciencia, Tecnología y Medio Ambiente, República de Cuba.

Sistemius. (2020). La protección jurídica del secreto empresarial. https://www.sistemius.com/la-proteccion-juridica-del-secreto-empresarial/.

Suñol Buské, A. (2016). Los secretos empresariales: Concepto y fundamento de su protección. https://almacendederecho.org/los-secretos-empresariales-concepto-y-fundamento-de-su-proteccion-i/.

Tobón Franco, N. (2009). Secretos industriales, empresariales y know how. Editorial Diké.

Valdéz Díaz, C. (2006). El objeto de la relación jurídica civil. Editorial Félix Varela.

Vázquez de Alvaré D. (2017). La competencia desleal en el mercado cubano. Editorial UNI IURIS.

\section{Legislación citada}

Decreto 343 del Consejo de Ministros, 10 de agosto de 2018, Gaceta Oficial Extraordinaria, número 40

Decreto 604, Ley de Propiedad Intelectual, artículo 177. http://www.transparenciafiscal.gob.sv/downloads/pdf/DC5111_30_Ley_de_Propiedad_Intelectual.pdf. 
Decreto Ley 199 Sobre la Seguridad y Protección de la Información Oficial, 2 de diciembre de 1999, Gaceta Oficial Ordinaria, número 78.

Decreto Ley 290 De las Invenciones Dibujos y Modelos Industriales, 1 de febrero de 2012, Gaceta Oficial Ordinaria, número 2.

Decreto Ley 336 De las disposiciones contractuales de Propiedad Industrial en los Negocios Jurídicos, 10 de agosto de 2018, Gaceta Oficial Extraordinaria, número 40.

Decreto Ley 337 De la Protección contra las prácticas desleales en materia de Propiedad Industrial, 10 de agosto de 2018, Gaceta Oficial Extraordinaria, número 40.

Ley 35 de Disposiciones sobre la Propiedad Industrial (LPI), artículo 83, 2008. http://www.sice.oas.org/int_prop/nat_leg/Panamá/L35b.asp\#titIVt.

Ley $57 / 2000$.

Ley 59, Código Civil de la República de Cuba, 17 de julio de 1987, Divulgación MINJUS, La Habana, 1988, artículo 81.

Ley 62, Código Penal, 30 de diciembre de 1987, Gaceta Oficial de la República de Cuba, Edición Especial, número 3, La Habana, 1987, artículo 226.

Ley $116 / 2014$.

Ley 118 De la Inversión Extranjera, 16 de abril de 2014, Gaceta Oficial Extraordinaria, número 20.

Reglamento de la Ley de Información no Divulgada/2000, https:/www.tra.go.cr/ NormativaRegistral/Reglamento\%20a\%20la\%20Ley\%20de\%20informaci\%C3\%B3n\%20no\%20divulgada.pdf.

Resolución 21 del Sistema Nacional de Propiedad Industrial, 7 de enero de 2003, Gaceta Oficial Ordinaria, número 10. 